\title{
Forças produtivas e compleições corporais: do trabalho braçal ao trabalho confinado
}

\author{
Maurício Beck ${ }^{1}$ \\ https://orcid.org/0000-0002-8681-1626 \\ ${ }^{1}$ Universidade Estadual de Santa Cruz, Programa de Pós-Graduação em Letras, Ilhéus, BA, Brasil
}

Forças produtivas e compleições corporais: do trabalho braçal ao trabalho confinado

Resumo: O presente artigo tem por objetivo desenvolver uma reflexão sobre o corpo do trabalhador, o trabalho do corpo e a imagética do corpo no entremeio das perspectivas da teoria materialista do discurso, do materialismo histórico, da genealogia foucaultiana, da historiografia brasileira e da sociologia do trabalho contemporâneo. Sem buscar ser exaustivo e sem visar uma complementaridade entre essas perspectivas, o artigo propõe a tese de um corpo histórico, cuja compleição, imagética, ideal e sofrimentos (dos corpos de trabalhadores e não trabalhadores) são sobredeterminados pela morfologia do trabalho de dada formação social. Como ilustração do atual trabalhador imóvel e confinado, abordam-se as condições contemporâneas do trabalho do operador de telemarketing. Por fim, tecem-se algumas considerações sobre imobilização e condicionamento dos corpos e o confinamento do trabalhador urbano durante o expediente laboral. Da exposição de novos modos de sofrimento no trabalho engendra-se uma crítica materialista da crítica hegemônica à corpolatria contemporânea.

Palavras-chave: Discurso. Compleição corporal. Trabalho confinado.

\section{Productive forces and body compositions: from manual labor to confined labor}

Abstract: This article aims to develop a reflection on the laborer's body, the body work and the body imagery in the midst of the discourse materialist theory perspectives, of the historical materialism, of the Foucaultian genealogy, of the Brazilian historiography and of the contemporary work sociology. Without seeking to be exhaustive and without aiming at a complementarity among these perspectives, the article proposes the thesis of a historical body, whose composition, imagery, ideal and sufferings (of the bodies of laborers and non-laborers) are overdetermined by work's morphology of the given social formation. As an illustration of the current immobile and confined laborer, the contemporary labor conditions of the telemarketing operator are addressed. Finally, some considerations are made about the bodies' immobilization and conditioning and the urban laborer's confinement during working hours. From the exposure of new means of suffering at work a materialist critique of contemporary body idolatry hegemonic criticism is generated.

Keywords: Discourse. Body composition. Confined labor.

Recebido em 15.02.2020. Aprovado em 07.04.2020. Revisado em 07.07.2020.

(C) O(s) Autor(es). 2020 Acesso Aberto Esta obra está licenciada sob os termos da Licença Creative Commons Atribuição-NãoComercial 4.0 Internacional (https://creativecommons.org/licenses/by-nc/4.0/deed.pt_BR), que permite copiar, distribuir e reproduzir em qualquer meio, bem como adaptar, transformar e criar a partir deste material, desde que para fins não comerciais e que você forneça o devido crédito aos autores e a fonte, insira um link para a Licença Creative Commons e indique se mudanças foram feitas. 


\section{Introdução}

A igreja diz que o corpo é uma culpa. A ciência diz que o corpo é uma máquina. A publicidade diz que o corpo é um negócio. E o corpo diz: eu sou uma festa. Eduardo Galeano

Discorrer sobre o corpo em uma perspectiva materialista é a proposta maior do presente texto. Para tanto, procederemos por uma abordagem multifacetada, tendo em conta a ênfase teórica e analítica que o corpo, enquanto objeto de investigação, ganhou nas décadas iniciais do século XXI. Serão apresentadas três perspectivas a guisa de introdução, o escopo é mostrar certa convergência entre elas, desde que tomemos a chave interpretativa do trabalho do corpo e do corpo do trabalhador. Ademais, faremos incursões pelos campos da historiografia, da sociologia do trabalho e, para arrematar, enfocaremos a morfologia laboral e os modos de sofrimento no trabalho da operadora de telemarketing.

A escolha do enfoque nas condições do ofício da teleoperadora se justifica tendo em vista que este ofício tem sido uma das principais vias de acesso ao trabalho formal para os jovens de centros urbanos, em especial na região nordeste do Brasil. Por outro lado, é nossa tese que a atual morfologia do trabalho urbano é condicionada pela imobilização e pelo confinamento do corpo do trabalhador, em contraste com o chamado trabalho braçal outrora majoritário. Consideramos o ofício do operador de telemarketing um caso típico do trabalho confinado.

\section{Vias de acesso ao corpo}

Para realizar uma reflexão sobre o corpo como discurso e como força produtiva, imaginamos vários caminhos muito diferentes. Uma primeira possibilidade seria a de abordar a circulação exponencial da imagem dos corpos na Sociedade do Espetáculo. Trataríamos, por um lado, de retomar as formulações de Guy Debord (1997, p. 14) sobre o espetáculo: "não um conjunto de imagens, mas uma relação social entre pessoas mediada por imagens". Por outro, teríamos também de atualizar algumas de suas reflexões, pois a invisibilidade do espectador anônimo das mídias do século passado deu lugar a uma crescente visibilização dos sujeitos, agora convertidos em atores de si mesmos, na vitrina digital das redes sociais. Captura, registro, exposição e circulação de imagens de corpos configuram cada vez mais intensamente nosso laço social.

Entretanto, o que parece marcar esse começo de século é uma convergência entre a Sociedade do Espetáculo, relação social mediada por imagens, com intensificação da interlocução entre sujeitos via redes sociais, constituindo um discurso que interpela indivíduos em sujeitos via selfies, storys, posts, compartilhamentos, comentários. Se uma imagem não vale mil palavras, pode magnetizar mais curtidas e cativar mais views. O sujeito se significa tornando-se mais visível. Já não tiramos fotografias para guardá-las em uma gaveta, mas para fazer circular nossas imagens, nossos rostos sorridentes, nossos corpos desejáveis (ou não) e nossas circunstâncias felizes ou nem tanto.

Outro caminho, mais pavimentado atualmente, seria partir para uma crítica ideológica do imaginário hipertrofiado do corpo. No intento de desconstruir os padrões estéticos de uma heteronomia coercitiva, aquela dos significados estabilizados da beleza magra ou atlética de corpos individualizados, apolíneos. Como efeito dessa crítica dois resultados possíveis: ou o sujeito desconstruído (falsa desidentificação voluntarista), ou o sujeito cínico (falsa desidentificação quietista) ${ }^{1}$. Em outros termos, o bom ou o mau alter ego do velho Barão de Münchhausen, supostamente cientes das causas que os determinam, citados por Pêcheux (1997)?

Terceiro caminho possível: levar a sério o materialismo de Marx, como disse certa vez Foucault (2007a), e primeiramente abordar não a ideologia, o discurso ou o imaginário do corpo, mas sua materialidade própria. Não a materialidade biofísica, mas a materialidade histórica do corpo em toda sua espessura. Tratar-se-ia, antes, de compreender o corpo inserido na base socioeconômica. Corpo mais ou menos arregimentado nas relações produtivas, compleição física como efeito de dadas condições de produção.

Trata-se do homem de ferro contra o homem de carne e osso. A subsunção de seu trabalho ao capital - a absorção de seu trabalho pelo capital -, que está no cerne da produção capitalista, surge aqui como um fator tecnológico. A pedra fundamental está posta: o trabalho morto no movimento dotado de inteligência e o vivo existindo apenas como um de seus órgãos conscientes. A conexão viva do corpo da oficina não se funda mais na cooperação, mas sim no sistema de máquinas que forma agora, a partir do movimento de um 
motor primário e do abarcamento da totalidade das oficinas, a unidade ampla à qual estas últimas, ao continuarem sendo compostas por trabalhadores, mantêm-se subordinadas. (MARX, 1994, p. 108).

Eis a contradição posta entre trabalho vivo e trabalho morto, entre homem e máquina. O corpo do trabalhador como um dos órgãos conscientes do corpo maquinal da indústria. Trabalho morto para Marx é outro nome para meios de produção. Isto quer dizer que todo rol de instrumentos, ferramentas, tecnologias - da enxada ao computador - é oriundo do trabalho braçal e simbólico humano (MARX, 1994). A labuta pregressa de uma infinidade de trabalhadores passados nos legou os atuais meios de produção. Os mesmos meios que agora assujeitam o trabalho vivo, os corpos e as mentes dos trabalhadores. São os meios de produção que engendram como efeitos colaterais dadas compleições corporais. Ou seja, não haveria nada de natural na compleição física de trabalhadores e de não trabalhadores.

Ora, esse corpo como produto do trabalho não deixa de estar presente mesmo em Foucault:

Não se trata de cuidar do corpo, em massa, grosso modo, como se fosse uma unidade indissociável, mas de trabalhá-lo detalhadamente; de exercer sobre ele uma coerção sem folga de mantê-lo ao nível mesmo da mecânica - movimentos, gestos, atitude, rapidez: poder infinitesimal sobre o corpo ativo. [...] Se a exploração econômica separa a força e o produto do trabalho, digamos que a coerção disciplinar estabelece no corpo o elo coercitivo entre uma aptidão aumentada e uma dominação acentuada. (FOUCAULT, 2007b, p. 118-119, grifo do autor).

Note-se, no entanto, que o foco foucaultiano é um sobretrabalho disciplinar que aumenta a potência produtiva, ao mesmo tempo em que enfraquece a potência política dos corpos. É nesse sentido, o do disciplinamento dos corpos, que Foucault diz ter levado mais a sério o materialismo de Marx. Eé esta genealogia de práticas disciplinares e de processos de normatização-individualização que Pêcheux alude em Só Há causa Daquilo que Falha "para que se comece, enfim, a compreender o processo de resistência-revolta-revolução da luta ideológica de classes". (PÊCHEUX, 1997, p. 303).

Corpo como objeto de práticas disciplinares para melhor inserção do trabalhador em dado modo de produção, eis a contribuição da genealogia de Foucault. Mas, se ajustarmos ainda mais o foco, o corpo do trabalhador pode ser definido como "uma força produtiva, um instrumento de produção, uma aparelhagem tecnológica que se define por suas relações complementares ou contraditórias com outras forças produtivas" (BRÖHM, 2007, p. 342). De modo que, em nossa leitura, o corpo não ganha força, não conforma sua (in)docilidade somente via práticas disciplinares engendradas para tanto. $\mathrm{O}$ corpo do trabalhador também se transforma pelo e no cerne do trabalho explorado. E transforma-se pela via da transformação que o trabalho social engendra nos meios circundantes. (Ou seja, nos meios de produção e nos meios de reprodução das condições de produção)._Com isso, inoculamos na genealogia disciplinar de Foucault (2007b), as transformações e contradições das relações de produção.

O entrecruzamento dos três caminhos evocados acima (o da análise das imagens dos corpos, o da crítica do ideal do corpo, e o da materialidade histórica dos corpos

O corpo do trabalhador também se transforma pelo e no cerne do trabalho explorado. E transforma-se pela via da transformação que o trabalho social engendra nos meios circundantes. (Ou seja, nos meios de produção e nos meios de reprodução das condições de produção). imbricados aos meios de produção) talvez seja a melhor al-

ternativa para responder certa questão intrigante: qual seria a correlação entre a mudança de ênfase, em nossas atuais atividades laborais, do dito trabalho braçal para o trabalho dito intelectual, a transformação na compleição de nossos corpos e as formas como os percebemos e os desejamos contemporaneamente?

Pode-se pensar, por exemplo, na imobilização do corpo no trabalho em contradição com o imaginário de beleza do corpo muscular, atlético e esbelto. Para além da crítica a este ideal de corpo, talvez caiba ler nele um indício de um problema de outra ordem: não apenas imperativo estético inalcançável, mas antes o sintoma de uma sutil forma de precariedade do trabalho sentado, confinado. Uma forma de sofrimento laboral que produz seus antídotos: formas de remediar o mal-estar da disciplina de imobilidade do corpo por meio de outras disciplinas, fitness.

Tratar-se-ia não tanto, ou tão somente, de criticar os ditos padrões de beleza e a disseminação pletórica de imagens na Sociedade do Espetáculo do Corpo de nossa época, mas de analisar as formas de existência 
concretas, as formas de trabalho, de rotina, de circulação e de precariedade a que estão sujeitos os corpos dos trabalhadores no capitalismo do século XXI. Pois,

\begin{abstract}
A força muscular humana foi fator predominante até, sobretudo, o advento das máquinas movidas a carvão, a vapor e especialmente o uso da energia elétrica. O declínio da necessidade de se contar com a força para a produção se fez acompanhar da valorização de habilidades físicas específicas, como a capacidade de manter o ritmo dos movimentos ou sua precisão. [...] adquirindo gestos disciplinados e hábitos musculares, os operários, vistos como "homens máquinas", seriam capazes de alcançar o máximo rendimento no trabalho, com um dispêndio mínimo de energia. (BERCITO, 2011, p. 375-376).
\end{abstract}

Para Orlandi, “o sujeito urbano é o corpo em que o 'capital' está investido" (2004, p. 28). Investimento de capital, que se aplica sobre os corpos de indivíduos tornados "homens máquinas". Capital como laço social que constitui o sujeito urbano por meio de um investimento simbólico, na ótica discursiva de Orlandi, mas também e, sobretudo, de um investimento econômico. Pois, para o capital, trata-se de interpelar sujeitos como mão de obra via contrato de trabalho. E, desse modo, inserir os corpos, devidamente arregimentados para a produção industrial ou dita pós-industrial, no espaço urbano do chão da fábrica, da cadeira do escritório, de atrás do balcão no comércio. Espaço fechado, confinado, delimitado que engendra corpos imobilizados em tarefas de rotina cronometrada.

\title{
Operadora de telemarketing: gestos simbólicos
}

Este mito [o de Sísifo] só é trágico porque seu herói é consciente. O que seria a sua pena se a esperança de triunfar o sustentasse a cada passo? O operário de hoje trabalha todos os dias de sua vida nas mesmas tarefas, e esse destino não é menos absurdo. Mas só é trágico nos raros momentos em que se torna consciente. Sísifo, proletário dos deuses, impotente e revoltado, conhece toda a extensão de sua miserável condição: pensa nela durante sua descida. (CAMUS, 2012, p. 123).

A Almaviva do Brasil constitui uma sociedade de Telemarketing e Informática do Grupo Almaviva, The Italian Innovation Company. Segundo a apresentação na homepage da empresa², a Almaviva é a líder italiana na oferta de soluções de Information \& Communication Technology, na estratégia de negócio com o foco no cliente e em sistemas de gestão de conhecimento para a administração pública, entidades de previdência e setores industrial e de telecomunicações, transporte e logística, território e ambiente, defesa e segurança, bancos e companhias de seguros. No Brasil, diferentemente de outros países, a Almaviva estabeleceu escritórios operacionais com a contratação em massa de operadores de telemarketing.

O outro lado da história é que a Almaviva é também alvo de centenas de reclamações trabalhistas, sobretudo em Maceió, uma das cidades em que opera desde 2013. As condições de trabalho da teleoperadora são reconhecidamente estressantes pelas próprias mídias do mercado, possivelmente devido à condição de trabalhador interpelado como intermediador de interesses entre consumidores descontentes e vigilantes empregadores. Ademais, a Almaviva tem sido acusada especificamente de impor ritmos acelerados de trabalho por meio de um severo controle do deslocamento físico dos funcionários. Entre os problemas de saúde mais frequentes encontram-se os de trato urinário. Foi relatado que os empregados da Almaviva recebiam uma squeeze, recipiente para líquidos, limitando a ingestão de água a uma quantidade delimitada, assim como somente poderiam usar o banheiro em dois pequenos intervalos de dez minutos durante o expediente de seis horas e vinte minutos (ALMEIDA; SIQUEIRA, 2016).

Há de se notar que estas condições de trabalho funcionam via imobilização dos corpos para maior eficácia das faculdades ditas intelectuais. A operadora de telemarketing deve fazer o uso mais eficaz e destro dos dispositivos tecnológicos na interlocução com o cliente. Sua força física é reduzida ao mínimo, sua destreza digital, sua acuidade visual, sua atenção e sua capacidade de verbalização e argumentação devem operar em um tempo cronometrado com precisão. A materialidade mais corpórea de seu ofício se concentra na modulação vocálica.

Muitas empresas de telemarketing padronizaram os diálogos - os scripts e os fluxogramas de atendimento são predeterminados -, objetivando facilitar a rotinização do trabalho das teleoperadoras, através da prescrição de uma norma de comportamento que direciona inclusive a entonação da voz. E o controle das emoções da teleoperadora pela empresa é outro fator importante: a teleoperadora deve ter autocontrole, para reverter situações de agressividade que frequentemente sofrem e manter o padrão de atendimento, tanto no que se refere ao tom da fala como também ao script predeterminado. (ANTUNES, 2014, p.48). 
O trabalho explorado se torna mais preciso, mais destro no manuseio do trabalho morto, e o corpo ainda mais imobilizado para a execução de tarefas especializadas, que não exigem nem força e nem deslocamento físico, mas apenas gestos digitais, regrados movimentos manuais para a execução cronometrada do dito trabalho simbólico. Trabalho este que não deixa de ser microfísico, labuta que ainda exige braços e dedos a seu dispor, enquanto o restante do corpo permanece imóvel, presumidamente em repouso. Em contraste com este suposto repouso corporal, o esgotamento não deixa de ocorrer, convergindo com os sofrimentos do trabalhador informal uberizado ${ }^{3}$. Ambos são instados a laborar dentro de um imperativo desempenho.

O sujeito de desempenho [empreendedor e explorador de si mesmo] esgotado, depressivo está, de certo modo, desgastado consigo mesmo. Está cansado, esgotado de si mesmo, de lutar consigo mesmo. [...] Desgasta-se correndo numa roda de hamster que gira cada vez mais rápida ao redor de si mesma. [...] Essa autocoação, que se apresenta como liberdade, acaba sendo fatal para ele. O burnout é o resultado da concorrência absoluta. (HAN, 2017, p. 91-100, grifo do autor).

Se o contraste do trabalho confinado com o trabalhador braçal é flagrante, o que não é tão evidente são as novas formas de sofrimento e as condições de precarização no mundo do trabalho confinado. Daí a necessidade de se problematizar a hierarquia entre o trabalho manual e o intelectual. Primeiro porque os supostos privilégios do dito trabalho intelectual de outrora foram corroídos em concomitância com o declínio da necessidade da força física no modo de produção capitalista contemporâneo. Para Baitello Júnior (2012, p. 75), "todos somos levados a crer que estar sentado significa estar ocupando um lugar de honra." Em contraste,

Ainda hoje, em recantos retirados do nosso Brasil, onde as casas ainda são de chão batido, encontramse comunidades e aldeias sem cadeiras. Simplesmente porque elas não são necessárias. Quem se agacha descansa e dispensa a cadeira. Se observarmos as crianças, vamos verificar que elas tendem a brincar agachadas ou sentadas no chão. Já nós adultos temos grande dificuldade para nos agacharmos e ficar agachados por longo tempo. As cadeiras já encurtaram nossos músculos e tendões. (BAITELLO JÚNIOR, 2012, p. 76).

Por conseguinte, se o corpo do trabalhador confinado de hoje diverge do corpo do trabalhador braçal de ontem, então as formas de sofrimento mudaram no mesmo sentido. De modo que é estranhamente familiar que o corpo ideal visto, por exemplo, no protagonista de ação cinematográfico, que se dissemina entre inúmeras mídias de nossa época seja feito à imagem e à semelhança do trabalhador braçal de outrora e de alhures.

Segundo Antunes (2014), surgiram novas morfologias no trabalho contemporâneo e o chamado proletariado de serviços se constitui como uma nova parcela da classe trabalhadora brasileira. Seus sofrimentos decorrem tanto da imobilização do corpo e do confinamento quanto da demanda pela sinergia sorridente exigida para dar conta de tensões entre capital, trabalho e consumo. Ou, ainda conforme Antunes, das exigências de metas, da rotinização do trabalho, do despotismo dos coordenadores e dos supervisores, dos baixos salários, dos adoecimentos por efeito das condições de trabalho. O mal-estar da teleoperadora é, em síntese, o de ter a obrigação de permanecer sentada e fazer semblante face às contradições da chamada sociedade do desempenho.

\section{Considerações Finais}

Desde o Fédon de Platão (387 a. C.), valora-se o que chamamos de corpo em contraste com o que chamamos de alma. É na voz de Sócrates, personagem maior daquele texto, que se estabelecem as clássicas dicotomias das filosofias ocidentais: corpo/alma, sentimento/razão, cópia/realidade, esquecimento/memória, mortalidade/imortalidade. De modo que o corpo abrigaria tudo que é tido como negativo nessa dicotomia. Na perspectiva do dualismo socrático-platônico, antes de a alma habitar um corpo, ela tinha como residência a cidade das Almas, lócus das ideias puras, da verdade do mundo e da essência das coisas. Não é errado supor nesta raiz platônica uma das matrizes ideológicas de determinados discursos de distanciamento do corpo e de suas paixões para se alçar à "verdade-em-si", a "beleza-em-si", o "conhecimento-em-si". Em vista disso, um dos escopos do presente texto foi empreender uma crítica da crítica acadêmica em torno das práticas e dos discursos associados à corpolatria. Com efeito, se, por um lado, a temática da cultura do corpo ou do culto ao corpo acaba deixando de lado o corpo no trabalho e o trabalho do corpo, por outro, a crítica predominante parece ainda imbuída da desvaloração platônica do corpo e da reafirmação implícita dos valores do "mundo das ideias", da vida intelectivo-teórica e, desse modo, deixa de perceber o quanto o "culto ao corpo" é ainda idealista e platônico. 
Na perspectiva materialista, o ideal do corpo belo e esbelto é acima de tudo um ideal (socioeconomicamente sobre determinado, não pura forma de manipulação de dada superestrutura) e, ao mesmo tempo, parece ser sintoma das contradições da atual morfologia do trabalho urbano, majoritariamente confinado. Morfologia que impõe a imobilização do corpo durante a maior parte do expediente, sem que qualquer esforço cardiovascular ou muscular seja necessário. Em contraste, os discursos médico, fitness, entre outros, demandam do atual trabalhador um investimento individualizado em outra disciplina (diferente daquela que primeiro imobilizou seu corpo) para romper com um suposto "estilo de vida sedentário". Desse modo, as contradições e precariedades da atual morfologia do trabalho são contornadas e deslocadas pela via da responsabilização individual do trabalhador confinado. Nosso Sísifo contemporâneo, proletário de serviços, labuta imóvel e, no final do expediente, ao invés de refletir sobre o sem sentido de sua vida, é instado a fazer trabalho muscular, se exercitar, e pagar para tanto.

\section{Referências}

ALMEIDA, C.; SIQUEIRA, V. Almaviva é acusada de adoecer operadores de telemarketing. Cada minuto, Maceió, mar. 2016. Disponivel em: https://www.cadaminuto.com.br/noticia/283897/2016/03/13/almavivae-acusada-de-adoecer-operadores-de-telemarketing. Acesso em: 10 out. 2019.

ANTUNES, R. Desenhando a nova morfologia do trabalho no Brasil. Estudos Avançados. São Paulo, v. 28, n. 81, p. 39-53, ago. 2014. Disponível em: http://www.scielo.br/scielo.php?script=sci_arttext\&pid=S0103-40142014000200004. Acesso em: 07 fev. 2020.

BALDINI, L. J. S.; DI NIZO, P. L. O Cinismo como prática ideológica. Estudos da Língua(gem), v. 13, n. 2, p. 131-158, dez. 2015. Disponível em: http://periodicos2.uesb.br/index.php/estudosdalinguagem/article/view/1305. Acesso em: 06 abr. 2020.

BAITELLO JUNIOR, N. O pensamento sentado: sobre glúteos, cadeiras e imagens. São Leopoldo: Ed. Unisinos, 2012.

BERCITO, S. de D. R. Corpos-máquinas: trabalhadores na produção industrial em São Paulo (décadas de 1930 e1940). In: DEL PRIORI; M.; AMANTINO, M. (org.). História do corpo no Brasil. São Paulo: UNESP, 2011. p. 371-404.

BRÖHM, J-M. “Depois de mim, o dilúvio!” Imagens da morte e da negação do corpo em Marx. In: NÓVOA, J. (org.). Incontornável Marx. Salvador. São Paulo: EDUFBA; EDUNESP, 2007. p. 339-367.

CAMUS, A. O Mito de Sísifo. Tradução de Ari Roitman e Paulina Watch. 2. ed. Rio de Janeiro: Bestbolso, 2012.

DEBORD, G. A Sociedade do Espetáculo. Tradução de Estela dos Santos Abreu. Rio de Janeiro: Contraponto, 1997.

FOUCAULT, M. Microfísica do Poder. Organização e tradução de Roberto Machado. Rio de Janeiro: Graal, 2007a.

FOUCAULT, M. Vigiar e Punir. História da Violência nas Prisões. Tradução de Raquel Ramalhete Petrópolis: Vozes, $2007 \mathrm{~b}$.

HAN, B. Sociedade do Cansaço. Tradução de Enio Paulo Giachini. Petrópolis: Vozes, 2017.

MARX, K. Maquinaria e trabalho vivo (os efeitos da mecanização sobre o trabalhador). Crítica Marxista, São Paulo, Brasiliense, v. 1, n. 1, p. 103-110, 1994.

ORLANDI, E. P. Cidade dos sentidos. Campinas, SP: Pontes, 2004.

PÊCHEUX, M. Semântica e Discurso: Uma Crítica à Afirmação do Óbvio. Tradução de Eni Pulcinelli Orlandi, Lourenço Chacon Jurado Filho, Manoel Luiz Gonçalves Corrêa e Silvana Mabel Serrani. São Paulo: Ed. Unicamp, 1997.

\section{Notas}

1 Quietista porque fatalista, desengajada. Ou seja, é uma forma cínica de o sujeito pertencer a uma dada formação discursiva pela via de "um certo modo de relação com o saber, em que o sujeito não se filia diretamente, nem se desfilia, mas permanece no horizonte de uma tomada de posição desengajada”. (BALDINI; DINIZO, 2015, p. 146). Em contraponto, a falsa desidentificação voluntarista imaginária se realizar por meio de uma vontade (ou atitude) plenamente engajada, com vistas a uma perfectibilidade moral. Pêcheux (1997) faz menção às contradições do quietismo, em que o tempo e a experiência trabalhariam a favor da revolução, não havendo razão para nenhuma intervenção teórica ou política frente ao determinismo da História; ou do salto voluntarista, posição de crença em um engajamento político e teórico todo poderoso. Ambas as posições perpassam a história do marxismo no século XX.

2 Disponível em: https://www.almavivadobrasil.com.br/pt-br/. Acesso em: 9 out. 2019.

3 Embora o motorista de Uber também tenha seu corpo imobilizado no interior do veículo automotivo, no caso dos entregadores do Ifood, serviço em crescimento nas cidades grandes e médias, na opção bicicleta, retomam o uso e abuso de certa força muscular e potência cardiovascular no exercício de atividade remunerada. Contudo, este parece ser uma exceção à regularidade do trabalho confinado.

\section{Maurício Beck}

pardalbeck@gmail.com

Doutorado pelo Programa de Pós-Graduação em Linguística e Literatura (UFAL)

Professor visitante do Programa de Pós-graduação em Letras: linguagens e representações (PPGL-UESC) 
UESC

Campus Soane Nazaré de Andrade, Rodovia Jorge Amado, km 16 - Bairro Salobrinho. Ilhéus - Bahia - Brasil

CEP: 45662-900

\section{Agradecimentos}

Agradeço a leitura de Lucimara Santa Fé e ao trabalho de tradução para o inglês do título e do resumo de Luana Thibes.

Agência financiadora

Não se aplica.

Contribuições das autoras

Não se aplica.
Aprovação por Comitê de Ética e consentimento para participação

Não se aplica.

\section{Consentimento para publicação}

Não se aplica.

Conflito de interesses

Não há conflito de interesses. 